Encrucijada/Crossroads: An Online Academic Journal

Issue 1, Volume 12003

\title{
Teaching Latino Culture/Creating Paths to Success: Mentoring Latino Students Through the Classroom
}

\author{
Ellen M. Gil-Gomez \\ Division of Comparative Studies in the Humanities \\ The Ohio State University
}

When I began thinking like a futurist about Latinos and Latino Studies in the 21 st century my mind went right to the importance of education. While this could be an obvious place for an educator to turn I felt it more important than as just reflective of my own work. With the recent projections of the expansion of the U.S. Latino population being much discussed, there does not seem to be an equally powerful discussion about the challenges the country will encounter to improve the lives of these Americans. Rather, the rhetoric generally turns to how to protect communities and services from these "newcomers." Thus, the educational system at all levels is being positioned as defensive and protective rather than dynamically and progressively incorporating future change. Paralleling this rhetoric of fear is the frightening continuation of the miseducation or the loss of education for the Latino community. It's not an understatement to say that the threats to Latinos in the new century begin early and go deep. Indeed, with statistics that reflect only 54\% of Latinos graduated high school in 1990, down from 62.9\% in 1985, the future is ominous (Heyck 2). ${ }^{1}$

While I have been lucky enough to make it through the educational system, to earn my doctoral degree and to now be a teacher, I've realized that I'm still not entitled to function as I would choose within the university educational system. While my desire is to give back to Latino/a students by helping them to negotiate the system, the institution of higher education itself has routinely made this effort difficult if not impossible. So, even though every institution where I've taught has, at every level, spoken the rhetoric of "diversity" or of "multicultural" education they all hampered my ability to formally mentor Latino/a students.

I have been given a number of reasons for the terrible state of Latino/a student mentoring in the institution which ranged from attacks on Affirmative Action and consequently the questioning of an Ethnic Studies curriculum, to the fear of appearing to promote "segregation" by allowing the possibility of Latino/a mentor groups, to the simple undervaluing of faculty service directly to Latino/a students and organizations. Thus, as a Latina professor who was hired to improve the diversity of an institution - in terms of representation and through developing academic programs - I routinely had to resort to measures that the same 
institution did not support because the leadership wanted me to be their symbol rather than part of a change that would positively affect students. ${ }^{2}$

While this has been an undeniable burden to me as an educator, I believe that my experiences are common for faculty of color and also reflect important systemic problems that need to be revealed so that Latino/a students can benefit from the knowledge and better control their own education. It's only been since teaching students of color regularly that I've fully realized the lie of equal access to education that our public institutions continue to hide behind. My resistance to this lie has forced me to work within my own borders. I've since developed my own ability to help create and use informal networks of Latino students, staff and faculty to address issues and provide a mentoring system that is, for the most part, still absent from the institution. And I've also refocused the content of my mentoring to encourage students to think about institutional processes rather than only finding comfort in building community intimacy, Latino culture and selfpreservation.

This has been particularly important in the last year with students riding a wave of confusion, or unbound optimism, over the newest Latino fad. I've found that recently many young Latinos/as have a false sense of comfort that has arisen through the media's valorization of Latino pop idols. Even with all of the current rhetoric of embracing the Latino "other" in the media with this new cycle of hype that proclaims the embracing of Latinos in America-"The Latin Boom" and previously the "Decade of the Hispanic" - the rhetoric does little to change the realities of Latino communities. ${ }^{3}$ In fact the media hype represents a lie that Latinos have a newly emergent power and status in the U.S. marketplace. If this is true, why do Latinos need "special" rights and treatment? Just within the last year I have seen an increased number of Euro-American students using this new wave of "celebration" as the "proof" that all is well in the melting pot. These students also feel that if population growth continues as the government projects it will very shortly be them who need "protecting" from this Latinization. Clearly the stage, the television, and the movie screen differ vastly from the street, the classroom, and the office. This newly emerging conflict is another example of the cultural schizophrenia mis-education that young Latinos/as must daily negotiate. The larger society daily communicates this new "truth" of Latino/a power and success whereas the majority of Latinos/as experience something very different.

It is generally true that U.S. Latino cultures encourage and promote community and personal connections as the primary roads to success. On the other hand, the academy does not generally validate these pathways, rather bureaucracy is the system and rhetoric is the language that is empowered. The personal and communal are to be left at the door if you are to be welcomed at the table. This culture clash can ultimately destroy both Latino/a students and faculty if they are unprepared for it and unsupported within it. I've witnessed the

Encrucijada/Crossroads 1.1 (2003): 47-56 
devastating consequences of this on numerous students as they suffer deep confusion about why they feel they are being dismantled by something that is supposed to be building them up.

This process of destruction can happen on a number of levels, all of which have profound consequences on students. They can be actively damaged by racist comments made by faculty and students in the classroom, they can be made to feel invisible and inconsequential by having Latinos/as ignored or absent from the university's curriculum, and they can be hampered in their own study by the lack of Latino/a faculty members and/or those knowledgeable about the field. Indeed, I recently had a Latina undergraduate tell me in frustration: "I made it to college and assumed I could just study. I've begun to find out that it's not that easy" (Medina). What's remarkable about this sentiment is not it's novelty but rather it's commonality for Latinos/as. Again, the schism grows and the choices shrink.

By turning a critical eye to this system of oppression that is currently built into the academy by demystifying if for Latino/a students, who are very commonly first generation college students, then they can learn strategies to defend themselves against this devastation and respond as they choose. They might work directly within existent Latino networks and organizations or equally importantly they might begin to feel entitled to a culturally relevant education in whatever field they choose. Connecting students to a larger network of options benefits the student and teacher because it does not only replicate the validity of the personal relationship but also the multiple functions of community networks. It also protects the teacher from being made indispensable to students and more able to balance her commitments as is necessary for professional survival. ${ }^{4}$

By balancing the importance of personal contact and institutional rhetoric Latino/a students and faculty can better advocate for issues important to their communities and at the same time find success in their educational and professional lives. Many times these two elements are seen in opposition as if one can't be both a professional and a community advocate. In my view this is a major factor in the sometimes-subtle mis-education of Latinos/as. Many are taught, either directly or indirectly, that they are at fault for their "passionate" but inappropriate responses to institutional problems. These reactions further push Latino/a students to the margins of the university. By learning strategies gleaned from faculty experience, students can have greater success in furthering their goals and agenda.

It is perhaps the curriculum that can make the biggest impact on Latinos/as. I do not primarily mean a curriculum that is well established and directed to a large Latino/a student population, although I don't undervalue the importance of Latino/a Studies in any arena. Rather, my experiences as a teacher are on campuses with a relatively small Latino/a population-including students, faculty and staff members - and with no institutionally recognized Latino/a 
Studies courses. In all cases I took a job in order to build courses for Latinos/as and other students of color. Because I have encountered, to varying degrees, the atmosphere that I've already described, I saw the power of the smallest classroom moments spent focused on Latinos/as.

Classrooms provide a validated space in a university where the place of Latinos/as is undervalued, attacked, or ignored. Latino/a Studies courses can celebrate Latino culture, educate non-Latinos on Latino experiences, and encourage Latinos/as to learn about the diversity and differences within their own community. An institutionalized space about Latinos/as and for Latinos/as can have a profound personal and professional impact. Indeed as Ana Castillo writes:

Learning about our [culture and history] is a way of learning about ourselves, an acceptance of oneself as an individual and of her/his people. Then we may educate the world, including our own communities about ourselves. But more importantly, it will show us another way of seeing life and the world we live in now. (Massacre 6)

There are clearly a variety of curricular contexts and institutionalized spaces wherein Latino/a Studies is taught or included. I have taught about Latinos/as in numerous contexts with a variety of results and I do feel it valuable to discuss these examples here in order to clearly illustrate the classroom's connection to the mentoring process. I focus here on the three main ways in which Latinos/as are included in the university curriculum and consider how each one of these avenues carries with it benefits and liabilities when considering its adequacy to further faculty mentoring in the classroom setting. Thus, I will not discuss how each example reflects the larger-and more hotly debated-issues of the narrowly focused university curricula or the ongoing lack of sensitivity to diverse cultures in higher education. Indeed my assumption, and my argument, is that as a whole the position of Latino/a studies in the university has been tenuous at best and clearly under fire from a range of disciplines and communities as non academic and unimportant. Therefore I have chosen to assume indisputable facts: Latino and Latina students will continue to enroll in our universities and they can be mentored through the inclusion of Latino/a Studies material in a range of curricula no matter how individual states, university systems, or campuses feel about the field. The three main frameworks within which university courses present Latinos/as are: as stand alone courses in Latino/a Studies, as topics courses within Latino/a Studies or other discipline, and as selected material or examples within a larger disciplinary discussion with no clear connection to Latinos/as.

I believe that the last example, the inclusion of Latinos/as as selected material or examples is currently the most common framework wherein students

Encrucijada/Crossroads 1.1 (2003): 47-56 
will have contact with Latino/a Studies. The liabilities to this approach are primarily the continued promotion of the illusion that Latinos/as are irrelevant in the "universal" version of events in core courses, and the varying levels of dismay and disappointment this "fact" has for Latino/a students. Latinos/as as example primarily posits that this community's issues are easily categorized and quantified and that they don't leak into the real concerns thus they easily remain positioned as "the other" in the classroom. Indeed, in this scenario Latino/a students can be called upon to give "expert" testimony about "their " experiences and ideas on these few occasions. These moments can enrage students sensitive to the abovementioned processes and at the very least embarrass them as being made to represent this "problem" group.

While the liabilities can be quite destructive in the hands of an insensitive instructor, at the same time an effective instructor can find numerous benefits and opportunities for mentoring in the same environment and context. Because courses that focus on a broad range of examples also tend to be introductory or major core courses by nature, the majority student population tends to be the majority in these classrooms as well. In other words, it can be fairly assumed that the majority of students are not signing up for the course in order to learn about the "one" Latino/a example. Therefore when the instructor uses class time to discuss Latinos/as within the course's broader context it can newly situate them as important and relevant. This small moment can do much to redress the routine silencing of Latino/a students. Most Latino/a students are trained not to expect to learn about themselves, their communities, or histories in the university classroom. Thus, in a site wherein it would be the norm to continue and even to promote this erasure, the smallest example can have profound impact.

In my experience it can have the most impact on those Latinos/as who wouldn't consider taking a specific Latino/a Studies course because they don't seem themselves as "political" or in need of the information. Young Latino/a students may even be encouraged to challenge their training of silence in a more deliberate way. ${ }^{5}$ In my classrooms these are the most common of the miseducated Latinos/as, those who feel that succeeding without changing the system, or even questioning it, is the goal. Indeed this is the group that educator and historian Rodolfo Acuña warns in his most recent edition of Occupied America when he says "the dream is over, wake up!" (462). ${ }^{6}$ For an instructor, it is no small success to encourage a student to take their first step out of their silence or denial and into a more active learning role. It should be clear then that any time a student is encouraged to see herself as an active agent in her own education a mentoring moment has occurred. ${ }^{7}$

The next most common curricular setting is where Latino/a Studies topics appear in other disciplinary contexts. These courses can sometimes have explicit disciplinary space or be taught under a topic heading only when a qualified 
instructor is available. Clearly on a programmatic level the difference between the two is enormous. However, again I'm focused here on the classroom's impact on students. Placing the issues concerning Latinos/as within other disciplinary boundaries can change students' perceptions of the "majority" versus "minority" territory. Consequently, it can serve to reterritorialize the entire disciplinary landscape. Latino/a students could both select these courses intentionally or take them for a specific major requirement thus the difference between the majority student population and the Latino/a students is not as drastic as in the previous example. An instructor in these circumstances has many opportunities to mentor Latino/a students. Students eager to take the course have the opportunity to learn and grow through an in depth study of the material, and to make a connection with a qualified instructor who might serve as an informal academic advisor, and/or as a means through which to discuss issues that affect Latinos/as in higher education. For those students who may have chosen the course for pragmatic reasons and not for the topic, they have the opportunity to be introduced to the field in the comfortable "home territory" of their discipline, and perhaps to be challenged as to how the material relates to their own interests. Latino/a students in these courses tend to feel more apart of the institutionalized process and are soon able to speak as themselves and not as a representative of anything in particular. They can also begin to bridge the more anecdotal or personal experience of their lives and families with the more foreign academic environment and processes through a Latino context.

The last framework I want to discuss here is the Latino/a Studies course within a larger program. Clearly this is the best place for Latino/a students who want to learn more about their own cultures and communities to go to do this study, as well as to find like-minded students. As instructor's mentoring in this setting can be far simpler because the elements of support are easily at hand: information and a support system. The one limitation I've found in these courses can be students' desire to sometimes personally bond over information rather than to think critically about it. In these instances less personal but more strategic mentoring can encourage students' need to do this community building, but also to emphasize the context and direct them to develop strategies in response to the problems they share. These contexts generally encourage students to build their own communities with each other and concurrently to imagine ways of using the institution to shape what they want for themselves and their larger communities.

I've come to believe that while there are real limitations for Latino/a students and faculty if there are no institutional systems in place to support them, there are also potential benefits to working in the margins. In my experience, the main benefit of this margin is the freedom to discuss issues that the institution itself doesn't recognize, or publicize, or would rather deny. Obviously, the majority easily ignores issues such as institutionalized racism, classism, white

Encrucijada/Crossroads 1.1 (2003): 47-56 
supremacy, entrenched power, and elitism. With the ability of different generations of Latinos/as to discuss these topics, formally or informally, a covert and potentially subversive training takes place. This training can provide an important alternative to the seduction of assimilation that so many times confronts students. To be educated about the complexities - the good and the bad-in one's own culture and community by those who value it and its place in the personal and academic journey, allows for more choices than just the "either/or" of assimilation and marginalization.

Indeed, it would also empower students to recognize the more common contradictions and complications that Latinos/as feel on a daily basis because we are routinely undecipherable to American society and its institutions-racially, ethnically, nationally, linguistically, culturally, economically and politically. The awareness of this very fact can initially give students comfort that they are not coming to their education with a deficiency, but more profoundly can help them value the training that they've already had as outsiders to the educational system in the United States. The majority of Latino/a students who enter the university do so with a skill that the academy claims to value most: critical analysis, thinking and awareness. Most have just not been trained to recognize these abilities in, and in their academic approaches, because it generally doesn't fit the model taught within the institution's boundaries.

By validating Latino culture and mentoring Latino students through academics and the workings of institutional power, faculty can teach students how to continue negotiating the cultural divides they encounter with collective support and historical consciousness and without sacrificing ourselves and our jobs. Again as Castillo has observed: "The ignorance of white dominant society about our ways, struggles in society, history, and culture is not an innocent and passive ignorance, it is a systematic and determined ignorance" (Massacre 5). Given this struggle mentoring should never be seen as an impediment to one's career as a teacher. Indeed it is with knowledge of the struggle that Latino/a teachers can find new ways to mentor students in any institution's margins. No Latino or Latina should be sacrificed to the institution's ignorance, rather we all need to teach and remind students and colleagues of its existence and of its power, and of the possibility of creating paths to success even through the largest of barriers. 


\section{Notes}

${ }^{1}$ Indeed the Almanac of Higher Education 1999-2000 reports when considering the educational attainment of the United States population (in 1990) over 30\% of Hispanics had only an $8^{\text {th }}$ grade education or lower. On the other end of the spectrum only $5.9 \%$ of Hispanics had completed a bachelor's degree.

${ }^{2}$ Perhaps this institutionalization of the symbolic at the heart of Ana Castillo's the "Stalinization of Chicanos/as in Academia" wherein she describes the myth that women of color academics are the most sought after and thus rewarded by academe. She states "a certain kind of woman of color, perhaps, one who will not make most of her colleagues too uncomfortable with her presence (such as one who is not U.S. born, and whose personal history is unencumbered by U.S. race and class experiences), and then she must contend over the next six years as to whether or not they will find her tenurable" (Massacre 211). Castillo aptly discusses the more common phenomenon that women of color experience in academe: "Because [politically minded women of color] stands at the bottom of the pyramid of institutional power, she is first made answerable to those who have 'brought her in' (usually claiming to be taking the reins into their command on the bases of fighting racism). And when such a woman does not see herself indebted to anyone and/or is unwilling to participate in the intrigue of in-house politics - she's out" (210).

${ }^{3}$ Ana Castillo describes the generation of Chicanos/Latinos who grew up in the 1980s whom she feels embraced the myth that rewards for the "Hispanic" had finally come. She critiques the emptiness of this unprecedented symbolism of "Hispanic" success that occurred through both media images - "Magazines, billboards and even television commercials (Coors comes to mind) showed young, brown, beautiful Latina models in flashy wear reaping some of the comforts and pleasures of a democracy based on free enterprise" (Massacre 31-32) - as well as individually tokenized political figures.

${ }^{4}$ This point can not be stressed enough, as the overwhelming numbers of Latino/a faculty members are in the junior rank or non-tenure track positions. This status of course leaves them extremely vulnerable to all attacks by the system that they may have to subvert in order to benefit Latino/a students. Again, according to The Almanac of Higher Education 1999-2000 in the Fall 1992 the number of full time faculty with teaching responsibilities were $86.8 \%$ white and $2.5 \%$ Hispanic. Within this percentage the total number of Hispanic faculty was $60 \%$ in the junior rank or in a variety of non-tenure track positions.

${ }^{5}$ For example if a survey course in American literature or history included Latino/a authors or figures alongside those considered "mainstream" or canonical it could do much to foreground a range of questions: who is American? What are the "masterpieces" and why? Who writes history? These initial questions lead one to a systematic analysis that could potentially uncover problems within university and disciplinary institutions and structures. The same kinds of question can occur to Latinos and non-Latinos alike and could, of course, be asked of other broadly conceived courses such as introductions to women's studies, sociology, psychology, anthropology, etc.

${ }^{6}$ Acuña sees as essential recontextualizing history and the educational system in order to challenge Chicano/Latino youth that perhaps, because of the successes of the past, can now too routinely see the world through American culture's optimism. He critiques this optimism thusly: "we allow myths such as we are 'Hispanics' to continue, rationalizing that we all have a common history. We repeat that we share a common culture, forgetting that the culture we share is a colonial one. In the end, it boils down to the fact that it is seductive to think of ourselves as

Encrucijada/Crossroads 1.1 (2003): 47-56 
powerful. The celebration of our success perpetuates the myths that Chicanas/os are doing just fine, they just have to wait for the immigrant to assimilate and they'll be up there with the Irish and the Italians who also made it. Time will cure all problems. An American education will recycle all of us. ... After all we made it. I think not" (464).

${ }^{7}$ In my experience it is most common for these previously silenced or unaware students to come to my office near the end of class, or even after, and "confess" the importance that the Latino/a examples had for them. Usually they have kept their distance from me during the term because they don't want to seem to be ingratiating themselves in order to get a better grade. They are generally aware of the possible inappropriateness that they use a personal networking strategy in the university setting. Usually these students don't drastically change their plans and change fields, for example, but report that they have begun to see themselves as "real" members of the classroom and no longer invisible. 
Gil-Gómez

\section{Works Cited}

Acuña, Rodolfo. Occupied America: A History of Chicanos. $4^{\text {th }}$ ed. New York: Longman, 2000.

The Almanac of Higher Education, 1999-2000. 1999. The Chronicle of Higher Education. 25 July 2000.

$<$ http://chronicle.com/free/almanca/1999/almanac.htm.

Castillo, Ana. The Massacre of the Dreamers: Essays on Xicanisma. 1994. New York: Plume, 1995.

Heyck, Denis Lynn Daly. "Introduction: Latinos, Past and Present." Barrios and Borderlands: Cultures of Latinos \& Latinas in the United States. Ed. Denis Lynn Daly Heyck. New York: Routledge, 1994. 1-15.

Medina, Lucia. Personal Interview. 17 July 2000.

Encrucijada/Crossroads 1.1 (2003): 47-56 